\title{
Complex Behaviour of Bile Salts at Various Temperatures Under the Influence of Antidepressant Drug (Imipramine) in Aqueous Solution
}

\author{
Shweta Singh ${ }^{1}$, Santosh K. Sar ${ }^{1, *}$, Tonmoy $\operatorname{Ray}^{2}$ \\ ${ }^{1}$ Department of Applied Chemistry, Bhilai Institute of Technology, Durg, (C. G.) India \\ ${ }^{2}$ Department of Biotechnology, National Institute of Technology, Durgapur, (W. B.) India
}

Email address:

Santoshsar@hotmail.com (S. K. Sar)

${ }^{*}$ Corresponding author

\section{To cite this article:}

Shweta Singh, Santosh K. Sar, Tonmoy Ray. Complex Behaviour of Bile Salts at Various Temperatures Under the Influence of Antidepressant Drug (Imipramine) in Aqueous Solution. Science Innovation. Vol.4, No.5, 2016, pp.235-241. doi: 10.11648/j.si.20160405.13

Received: September 23, 2016; Accepted: October 6, 2016; Published: November 7, 2016

\begin{abstract}
The present method was based on the effect of bile salt (Sodium cholate and Sodium deoxy cholate) on the dissolution of Antidepressant drug like Imipramine. Sodium cholate and Sodium deoxycholate is a type of anionic surfactants form mixed micelle with Imipramine and influence its rate of dissolution. The micellization behavior of binary anionic bile salt surfactant mixtures was investigated by conductivity method and various thermodynamical parameters are calculated. The results of the study have been analyzed by using Clint's, Rubingh's, and Motomura's theories for mixed binary systems.
\end{abstract}

Keywords: Antideprassant Drug, Sodium Cholate, Sodium Deoxycholate, Conductometer, Critical Micelle Concentration, Counter Ion Dissociation

\section{Introduction}

Surfactants word is made up of three different word "surface active agent". It has two different part -water-loving or hydrophilic and water-hating or hydrophobic. Due to presence of its unique structure it is also known as amphiphilic or amphipathic molecules and due to its nature hydrophilic group of Surfactants forms hydrogen bonds with water molecules, while due to hydrophobic nature hydrocarbon chains aggregate and moving away from the water molecules. Due to these properties surfactants is soluble in water. In aqueous solutions, they form organized bunch like structures called micelles. Surfactants are further classifies in to various part according to functional group present in it is-Anionic, Cationic, Zwitter ionic, Nonionic and Gemini surfactants.

Surfactants play important role in almost every sector of industry like oil recover, pharmaceutical, physical and organic chemistry, cosmetic industry, food science etc. Micelles have importance property in various industries but basically it play important role in pharmaceutical industry because it have ability to dissurf solve sparingly soluble active substance like drug in aqueous solution. Important role of micelle is in delivery of drug towards targeted area and increase its bioavaibility. It also attempt to minimize drug degradation, its loss and to prevent its harmful side effects (16).

Micelles as drug carriers present some advantages when compared to other alternatives such as soluble polymers and liposomes. Micellar systems can solubilize poorly soluble drugs and thus increase their bioavailability, they can stay in the body (blood) long enough to provide gradual accumulation in the required area, and their sizes permit them to accumulate in areas with leaky vasculature (9).

In general, surfactants play an important role basically in pharmaceutical biotechnology fields, since they are largely utilized in various drug dosage forms to control wetting, stability, bioavailability, among other properties (1). It is important to notice that lyophobic colloids, such as polymers, require certain energy to be applied for their formation, are quite unstable from the thermodynamic point of view, and frequently form large aggregates. Association colloids such as micelles, on the other hand, can form spontaneously under certain conditions (self- assembling systems), and are 
thermodynamically more stable towards both dissociation and aggregation (9).

In this work, we provide are view of micellar solubilisation of drugs in surfactant systems, blending it with basic information on surfactants structure and properties, as well as the applications for drug delivery. The main aim of our investigation was to study the influence of varying structures of the hydrophobic regions of selected anionic surfactants on the physico-chemical properties and the synergism effect in the bile salt and-anionic binary systems.

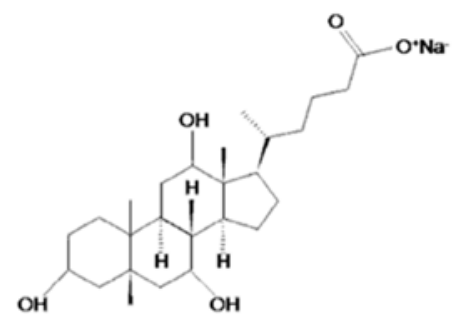

Fig. 1. Sodium Cholate.

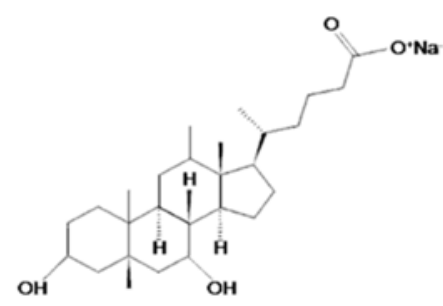

Fig. 2. Sodium deoxycholate.

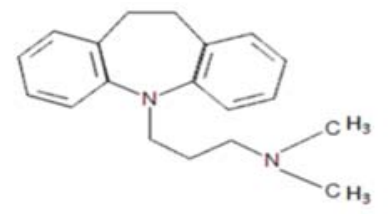

Fig. 3. Imipramine.

\section{Experimental}

\subsection{Materials}

The bile surfactants sodium cholate and sodium deoxycholate having anionic nature which is used in experiment was produced from LOBA Chemic and Imipramine. All the solutions were prepared in triple distilled water.

\subsection{Determination of Critical Micellization Concentration Value of Binary Mixtures}

In this experiment micellization tendency is determined by conductometric method because pure water or unionized water is a good insulator of electricity. If any charge or soluble ions present in it then it allow flowing current through aqueous solution. Thus the amount of current flow is used to calculate its ionic concentration.
Table 1. Experimentally obtained critical micelle concentrations of the Sodium deoxy cholate with Imipramine in various concentrations.

\begin{tabular}{llll}
\hline $\begin{array}{l}\text { concentration } \\
\text { of SDC(mM) }\end{array}$ & $\begin{array}{l}\text { Concentration of } \\
\text { Imipramine(mM) }\end{array}$ & $\begin{array}{l}\text { CMC } \\
(\mathbf{m M})\end{array}$ & $\alpha$ \\
\hline 0.1 & 0.1 & 0.016 & 0.0181 \\
0.09 & 0.1 & 0.0189 & $4.28 \times 10^{-3}$ \\
0.08 & 0.1 & 0.022 & 0.166 \\
0.07 & 0.1 & 0.017 & 0.08 \\
0.06 & 0.1 & 0.01 & 0.772 \\
0.05 & 0.1 & 0.0375 & $3.95 \times 10^{-3}$ \\
0.04 & 0.1 & & \\
0.03 & 0.1 & 0.0216 & 0.077 \\
0.02 & 0.1 & 0.0075 & 1.7 \\
0.01 & 0.1 & 0.00423 & 0.0272 \\
\hline
\end{tabular}

Table 2. Experimentally obtained critical micelle concentrations of the Sodium cholate with Imipramine in various concentration satroomtemperature.

\begin{tabular}{llll}
\hline $\begin{array}{l}\text { concentrationof } \\
\text { SC(mM) }\end{array}$ & $\begin{array}{l}\text { ConcentrationofImipra } \\
\text { mine(mM) }\end{array}$ & $\begin{array}{l}\text { CMC } \\
(\mathbf{m M})\end{array}$ & $\alpha$ \\
\hline 0.1 & 0.1 & 0.0166 & 0.0266 \\
0.09 & 0.1 & 0.019 & 0.136 \\
0.08 & 0.1 & 0.0225 & 0.031 \\
0.07 & 0.1 & 0.0283 & 0.09 \\
0.06 & 0.1 & 0.0133 & 0.225 \\
0.05 & 0.1 & 0.0107 & 0.088 \\
0.04 & 0.1 & - & - \\
0.03 & 0.1 & 0.0092 & 0.109 \\
0.02 & 0.1 & 0.01 & 0.148 \\
0.01 & 0.1 & 0.00916 & 0.116 \\
\hline
\end{tabular}

The CMC of the binary mixtures (Bile salt and Drugs) were studied using conductivity measurements, at different mole fractions and different temperature [6]. Prepared mixtures consisted of 0.1-1 mole fractions of Sodium cholate and Sodium deoxycholate and 0.1 mole fraction of Imipramine.

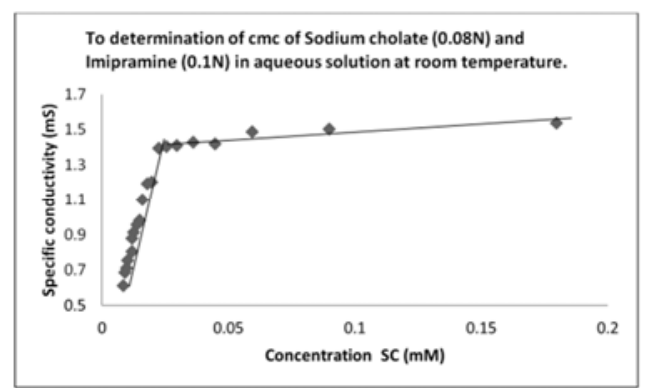

Fig. 4. To determination of $\mathrm{cmc}$ of Sodium cholate and Imipramine in aqueous solution at room temperature.

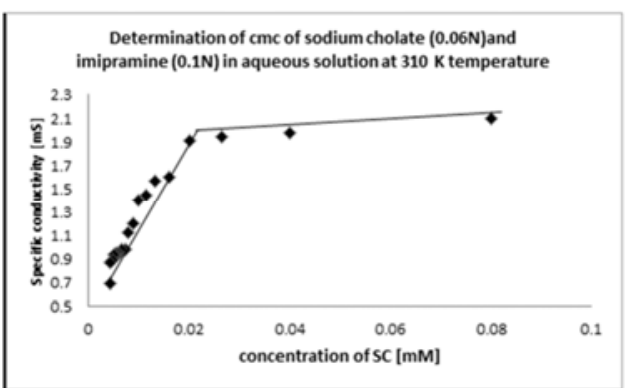

Fig. 5. To determination of cmc of Sodium cholate and Imipramine inn ueoussolutionat310Ktemperature. 


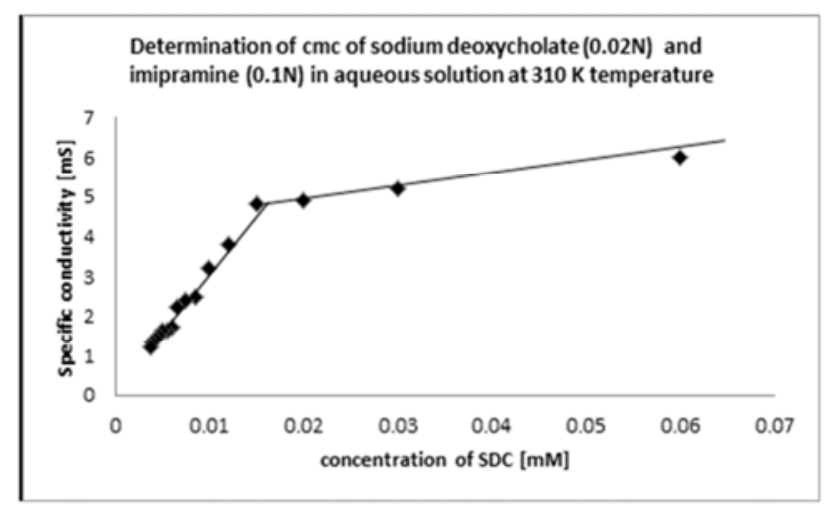

Fig. 6. To determination of $\mathrm{cmc}$ of Sodium deoxycholate and Imipramine in aqueous solution at $310 \mathrm{~K}$ temperature.

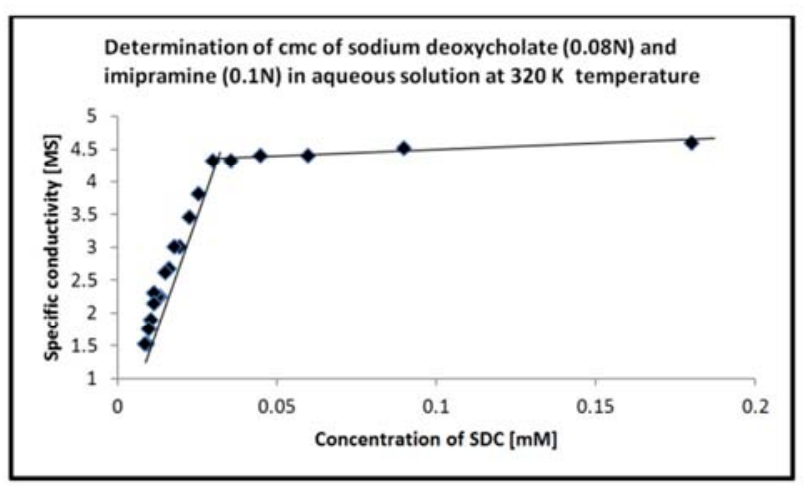

Fig. 7. To determination of $\mathrm{cmc}$ of Sodium cholate and Imipramine in aqueous solution at $320 \mathrm{~K}$ temperature.

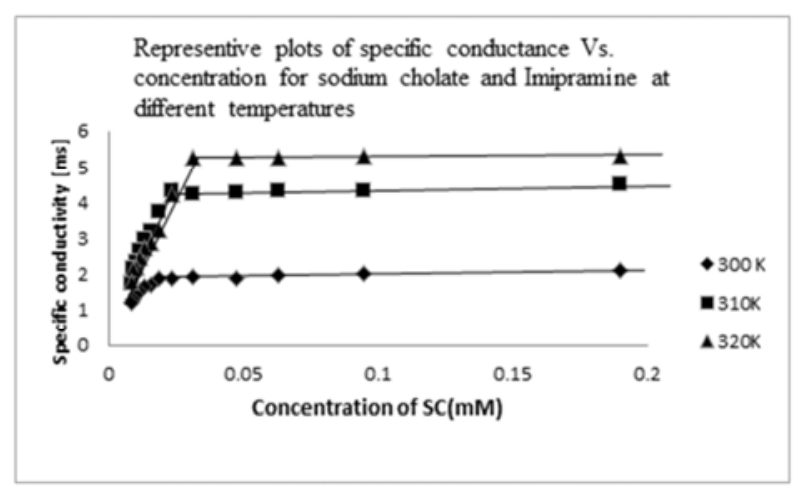

Fig. 8. Representive plot of Specific conductivity and concentration of Sodium cholate and Imipramine at various temperature.

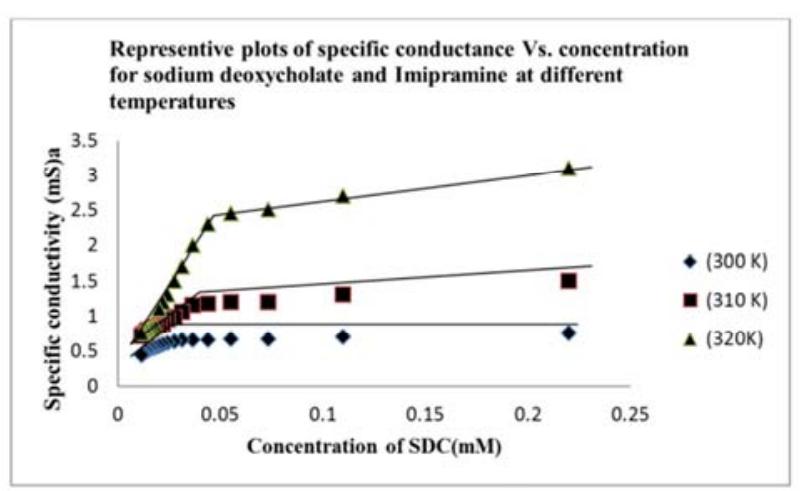

Fig. 9. Representive plot of Specific conductivity and concentration for Sodium deoxycholate and Imipramine at various temperatures.
The cmc values for individual non ionic surfactants and Imipramine were obtained through conductometric measurements.

Table 3. Experimental critical micelle concentration of the individual surfactants.

\begin{tabular}{llll}
\hline Surfactants & SC(mM) & SDC(mM) & Imipramine(mM) \\
\hline $\mathrm{Cmc}^{\mathrm{ex}} / \mathrm{mM}$ & 12 & 6 & 0.00909 \\
\hline
\end{tabular}

\subsection{Effect of Drugs on the Micellization Processs of BileSalts}

\section{Thermodynamics of micellization}

Surfactant concentration is increases gradually after sometime it reaches at particular concentration which shows deviation between premiceller region and postmiceller region known as cmc, from where micelle form is spontaneous. This means the free energy of surfactants molecule of micelle is always beless than the monomeric surfactants molecule when dissolving in distilled water. All the thermodynamics parameters are temperature dependent.[34].

The Gibbs free energy of micellization $\Delta \mathrm{G}_{\mathrm{m}}^{\mathrm{o}}$ was calculated by using following equation-

$$
\Delta \mathrm{G}_{\mathrm{m}}^{\mathrm{o}}=(2-\alpha) \mathrm{RT} \ln \mathrm{X}_{\mathrm{cmc}}
$$

The Calculated value of parameter is shown in Table 4 and 5 at various temperature range. The $\Delta \mathrm{G}_{\mathrm{m}}^{\mathrm{o}}$ is decrease with increasing temperature, this value show that the micellization process is spontaneous in aqueous mixtures and magnitude of hydrophobic effect is increases with increasing temperature.[34] (Table 4 and 5).

The $\Delta \mathrm{H}^{\mathrm{o}}{ }_{\mathrm{m}}$ can be derived by the Von't Hoff equation.

$$
-\Delta \mathrm{H}_{\mathrm{m}}^{\mathrm{o}}=(2-\alpha) \mathrm{RT}^{2}\left(\frac{d \ln X_{c m c}}{d T}\right)
$$

The result also shows that standard enthalpy of micellization is negative which indicates that the micelle formation process is exothermic which show strong interaction between drug and bile salts [34].

The $\Delta S^{o}$ was determined from the calculated values of $\Delta \mathrm{G}_{\mathrm{m}}^{\mathrm{o}}$ and $\Delta \mathrm{H}^{\mathrm{o}}{ }_{\mathrm{m}}$ by the help of following relationship

$$
-\mathrm{T} \Delta \mathrm{S}_{\mathrm{m}}^{\mathrm{o}}=\left(\Delta \mathrm{G}_{\mathrm{m}}^{\mathrm{o}}-\Delta \mathrm{H}_{\mathrm{m}}^{\mathrm{o}}\right)
$$

The $\Delta \mathrm{S}_{\mathrm{m}}^{\mathrm{o}}$ is always being positive which indicate that the process of micellization is entropy dominated over the micelle formation process. The positive value of $\Delta \mathrm{S}_{\mathrm{m}}^{\mathrm{o}}$ is due to the hydrophobic interaction between the surfactants and water molecule. [34, 5].

\subsection{Development of Model}

The present study provides an insight in to the mechanism of interaction of bile salts with various drugs like Imipramine. Based on the experimental findings it is possible to propose the concentration ranges involved with different stages of changes in the solubilisation of drugs by Sodium cholate and sodium deoxycholate. The experiments showed 
that the concentration of a bile salt needed to bring about a certain change in the drugs is strongly dependent on the absolute concentrations of bile salt and not on their molar ratio. The bioavailability of orally administered drugs can be in fluenced by interacting with food constituent and by physico-chemical conditions in the upper gastrointestinal tract. Normally, bile salts enhance the transport of lipophilic drugs across mucosal membranes. Bile salts are able to form stable mixed micelles consisting of fatty acids and phospholipids. Conventional micellar systems are known to solubilize lipophilic drugs having a low bioavailability [38].

Surfactant (bile salt) added in the drug and distilled water solution, then the dissolution rate of the Imipramine tablets increases (Shown in Table 1 and 2). It concludes that even presence of small concentration of bile salts is very helpful for the dissolution of various drugs [36].

In method to observing the influence of the structure of drug on formation of mixed micelles [4] with SDC and SC, physicochemical values of micelles and mixed micelle were calculated by using experimental $\mathrm{cmc}$ values which is shown in table 4- 5.

$\mathrm{cmc}^{\text {id }}, \mathrm{x}^{\text {id }}, \mathrm{X}_{1}$ and the $\beta$ parameter all were calculated by using following equation $[6,16]$.

The $\mathrm{cmc}^{\mathrm{id}}$ parameter indicates non ideal behavior if it differs from $\mathrm{cmc}^{\mathrm{ex}}$. The values of $\mathrm{x}^{\mathrm{id}}$ and the $\mathrm{x}_{1}$ are used to calculate the $\beta$ parameter. Critical micelle concentrations according to Clint' stheory of ideal mixtures ( $\left.\mathrm{cmc}^{\text {id }}\right)$

$$
\frac{1}{c m c^{i d}}=\frac{\propto_{i}}{c m c_{1}}+\frac{1-\propto_{i}}{c m c_{2}}
$$

The $\mathrm{cmc}^{\text {id }}$ values are presented and compared to the experimental $\mathrm{cmc}\left(\mathrm{cmc}^{\mathrm{ex}}\right)$ in Table 8 and 9 [3]. Deviation of the experimentally obtained $\mathrm{cmc}$ values from those calculated according to Clint's theory indicates nonideal behavior of examined surfactant mixtures and mutual interactions of the surfactants in the micelles. According to this experimental cmc are always being smaller than those predicted using models. The mole fraction of the more hydrophobic surfactant in the ideal mixed micelle $\left(\mathrm{x}^{\text {id }}\right)$, according to Motomura [4, 18], was calculated using the following relationship:

$$
X^{i d}=\frac{c m c_{2} \propto}{c m c_{2} \propto+c m c_{1}(1-\propto)}
$$

The $\mathrm{x}_{1}$ value was calculated by using following relation:

$$
1=\frac{X_{1}^{2} \ln \left(c m c^{e x} \propto / c m c_{1} X_{1}\right)}{\left(1-x_{1}\right)^{2} \ln \left[c m c^{e x}(1-\propto) / c m c_{2}\left(1-X_{1}\right)\right]}
$$

The $X^{\text {id }}$ and the $X_{1}$ values for the mixed micelles are presented in Table 8 and 9. Further according to Rubingh [5, 19], $X_{1}$ value was used to calculate the $\beta$ interaction parameter, through the following equation:

$$
\beta=\frac{\ln \left(c m c^{e x} \propto / c m c_{1} X_{1}\right)}{(1-X)^{2}}
$$

$\beta$ values explain the synergism or antagonism between two surfactants in mixed micelles. Its negative value indicate attractive interactions (synergism) between components of mixed micelles of drug and bile salt, The less negative value means the weaker synergistic interaction while positive values shows antagonistic interactions between surfactants in a mixture. Its value also shows the deviation between experimentally obtained $\left(\mathrm{cmc}^{\mathrm{ex}}\right)$ and calculated $\left(\mathrm{cmc}^{\mathrm{id}}\right) \mathrm{cmc}$ values [As referred in reference 5].

\section{Conclusion}

Binary combinations of bile salt and antidepressant drug (Imipramine) are studied. Aggregation of drug and bile salts as well as their tendency to form mixed micelles having CMC's different than ideal conditions, and the nonideality is more for the binary mixtures. The critical micelle concentration and thermodynamic parameters were studied using conductometric and surface tension method. The binary mixture of both surfactants and drug mixture was analysed by conductometer methods. The CMC and $\alpha$ value of sodium cholate (SC) and sodium deoxycholate (SDC) and drug (Ametreptylene) mixtures were determined in aqueous solvent mixture. It was observed that both values were depending on concentration of mixed surfactants, solvent and temperature. It was observed that micellization tendency of SC and SDC decreases in the presence of mixed micelle. The thermodynamic parameters of the process of micellization have been calculated for each system. $\Delta \mathrm{G}_{\mathrm{m}}^{\mathrm{o}}$ is negative and becomes less negative with increase in concentration of mixed surfactants and solvent mixture. This suggests that the micellization formation becomes less spontaneous with increasing amount of surfactants and solvents. The entropy of micellization is positive indicates that the micellization process is somewhat entropy dominated. Thus the values of $\mathrm{CMC}, \Delta \mathrm{H}_{\mathrm{m}}^{\vartheta}$ and $\Delta \mathrm{S}_{\mathrm{m}}^{9}$ increase, while the value of $\Delta \mathrm{G}_{\mathrm{m}}^{9}$ decrease with the increase of temperature.

The results of the study have been analysed using Clint's, Rubingh's, and Motomura's theories for mixed binary systems [7]. The critical micelle concentration of the ideal mixed micelle, the mole fraction of the more hydrophobic surfactant in the ideal mixed micelle, the mole fraction of the more hydrophobic surfactant in the real mixed micelle, and the $\beta$ interaction parameter of the mixed micelles were calculated by using experimental values obtained [6]. It was concluded that increased synergistic interactions can be due to the large number of hydrophilic groups present in the bile salts. 
Table 4. Critical micelle concentration and $\alpha$ value of various concentrations of Sodium Deoxycholate (SDC) and Imipramine at different temperatures.

\begin{tabular}{|c|c|c|c|c|c|c|c|}
\hline \multicolumn{2}{|c|}{ SDC+Imipramineconcentration } & \multicolumn{6}{|c|}{ Temperature(Kelvin) } \\
\hline \multirow{2}{*}{ SDC(mM) } & \multirow{2}{*}{ Imipramine(mM) } & \multicolumn{2}{|c|}{300} & \multicolumn{2}{|l|}{310} & \multicolumn{2}{|l|}{320} \\
\hline & & CMC (mM) & $\alpha$ & $\mathrm{CMC}(\mathrm{mM})$ & $\alpha$ & CMC(mM) & $\alpha$ \\
\hline 0.1 & 0.1 & 0.0166 & 0.0181 & 0.0181 & 0.27 & 0.02 & 0.266 \\
\hline 0.09 & 0.1 & 0.019 & $4.28 \times 10^{-3}$ & 0.023 & 0.03 & 0.0316 & $3.17 \times 10^{-3}$ \\
\hline 0.08 & 0.1 & 0.0225 & 0.166 & 0.018 & 0.028 & 0.03 & 0.032 \\
\hline 0.07 & 0.1 & 0.017 & 0.08 & 0.021 & 0.028 & 0.024 & $2.9 \times 10^{-3}$ \\
\hline 0.06 & 0.1 & 0.01 & 0.772 & 0.0114 & $9.01 \times 10^{-3}$ & 0.016 & 0.14 \\
\hline 0.05 & 0.1 & 0.0375 & $3.95 \times 10^{-3}$ & 0.0093 & $4 \times 10^{-3}$ & 0.0125 & 0.016 \\
\hline 0.04 & 0.1 & - & - & - & - & - & - \\
\hline 0.03 & 0.1 & 0.0216 & 0.077 & 0.0081 & 0.025 & 0.0108 & 0.225 \\
\hline 0.02 & 0.1 & 0.0075 & 0.148 & 0.015 & 0.074 & 0.02 & 0.0238 \\
\hline 0.01 & 0.1 & 0.0042 & 0.116 & 0.0045 & $6.81 \times 10^{-3}$ & 0.0061 & 0.01 \\
\hline
\end{tabular}

Table 5. Critical micelle concentration and $\alpha$ value of various concentrations of Sodium Cholate (SC) and Imipramine at different temperatures.

\begin{tabular}{|c|c|c|c|c|c|c|c|}
\hline \multicolumn{2}{|c|}{ SC+Imipramineconcentration } & \multicolumn{6}{|c|}{ Temperature(Kelvin) } \\
\hline \multirow{2}{*}{$\mathrm{SC}(\mathrm{mM})$} & \multirow{2}{*}{ Imipramine(mM) } & \multicolumn{2}{|c|}{300} & \multicolumn{2}{|l|}{310} & \multicolumn{2}{|l|}{320} \\
\hline & & $\mathrm{CMC}(\mathrm{mM})$ & $\alpha$ & $\mathrm{CMC}(\mathrm{mM})$ & $\alpha$ & $\mathrm{CMC}(\mathrm{mM})$ & $\alpha$ \\
\hline 0.1 & 0.1 & 0.0166 & 0.0266 & 0.022 & 0.16 & 0.04 & 0.011 \\
\hline 0.09 & 0.1 & 0.019 & 0.136 & 0.0316 & 0.05 & 0.047 & 0.082 \\
\hline 0.08 & 0.1 & 0.0225 & 0.031 & 0.03 & 0.041 & 0.045 & 0.133 \\
\hline 0.07 & 0.1 & 0.0283 & 0.09 & 0.0425 & 0.081 & 0.056 & 0.265 \\
\hline 0.06 & 0.1 & 0.0133 & 0.225 & 0.02 & 0.437 & 0.04 & 0.015 \\
\hline 0.05 & 0.1 & 0.0107 & 0.088 & 0.015 & 0.047 & 0.025 & 0.015 \\
\hline 0.04 & 0.1 & - & - & 0.0125 & 0.148 & - & - \\
\hline 0.03 & 0.1 & 0.0092 & 0.109 & 0.0108 & 0.06 & 0.0162 & 0.153 \\
\hline 0.02 & 0.1 & 0.01 & 0.148 & 0.01 & 0.176 & 0.015 & 0.173 \\
\hline 0.01 & 0.1 & 0.00916 & 0.116 & 0.0078 & 0.227 & 0.011 & 0.028 \\
\hline
\end{tabular}

Table 6. Thermodynamic parameters for the micellization of various concentration of sodium deoxycholate (SDC) with Imipramine [34].

\begin{tabular}{|c|c|c|c|c|c|c|c|c|c|c|c|}
\hline \multicolumn{4}{|c|}{ SDC+Imipramine(300K) } & \multicolumn{4}{|c|}{ SDC+Imipramine(310K) } & \multicolumn{4}{|c|}{ SDC+Imipramine(320K) } \\
\hline CMC & $\begin{array}{l}\Delta \mathbf{G}_{\mathrm{m}}^{\circ} \\
(\mathrm{kJ} / \mathrm{mole})\end{array}$ & $\begin{array}{l}\Delta \mathbf{H}_{\mathrm{m}}^{\circ} \\
(\mathrm{kJ} / \mathrm{mole})\end{array}$ & $\begin{array}{l}\Delta \mathbf{S}_{\mathrm{m}}^{\circ} \\
(\mathrm{kJ} / \mathrm{mole})\end{array}$ & CMC & $\begin{array}{l}\Delta \mathbf{G}_{\mathrm{m}}^{\circ} \\
(\mathrm{kJ} / \mathrm{mole})\end{array}$ & $\begin{array}{l}\Delta \mathbf{H}_{\mathrm{m}}^{\circ} \\
(\mathrm{kJ} / \mathrm{mole})\end{array}$ & $\begin{array}{l}\Delta \mathbf{S}_{\mathrm{m}}^{\circ} \\
(\mathrm{kJ} / \mathrm{mole})\end{array}$ & CMC & $\begin{array}{l}\Delta \mathbf{G}_{\mathrm{m}}^{\circ} \\
(\mathrm{kJ} / \mathrm{mole})\end{array}$ & $\begin{array}{l}\Delta \mathbf{H}_{\mathrm{m}}^{\circ} \\
(\mathrm{kJ} / \mathrm{mole})\end{array}$ & $\begin{array}{l}\Delta \mathbf{S}_{\mathrm{m}}^{\circ} \\
(\mathrm{kJ} / \mathrm{mole})\end{array}$ \\
\hline 0.0166 & -74.26 & -13.81 & 201 & 0.018 & -66.33 & -12.82 & 255 & 0.02 & -68.45 & -13.75 & 170 \\
\hline 0.019 & -74.11 & -37.98 & 120 & 0.023 & -75.5 & -40.03 & 114 & 0.031 & -76.39 & -43.24 & 103 \\
\hline 0.0225 & -67.33 & -19.73 & 158 & 0.018 & -75.94 & -22.66 & 171 & 0.03 & -75.56 & -24.09 & 160 \\
\hline 0.017 & -71.83 & -25.36 & 131 & 0.021 & -75.11 & -27.81 & 152 & 0.024 & -77.82 & -30.02 & 149.3 \\
\hline 0.01 & -47.64 & -21.59 & 86.83 & 0.011 & -79.02 & -37.38 & 134 & 0.016 & -74.52 & -37.21 & 116 \\
\hline 0.0375 & -70.74 & 82 & 509 & 0.009 & -80.23 & 87.59 & 541 & 0.012 & -80.7 & 92.75 & 542 \\
\hline- & - & - & - & - & - & - & - & - & - & - & - \\
\hline 0.0216 & -70.79 & 49.87 & 402 & 0.008 & -80.08 & 53.25 & 430 & 0.010 & -72.97 & 52.37 & 391 \\
\hline 0.0075 & -11.83 & -11 & 2.76 & 0.015 & -75.08 & -75.46 & -1.2 & 0.02 & -78.01 & -82.5 & -14.03 \\
\hline 0.0042 & -80.65 & -2.71 & 259 & 0.004 & -83.79 & -2.92 & 260 & 0.006 & -84.83 & -3.11 & 255 \\
\hline
\end{tabular}

Table 7. Thermodynamic parameters for the micellization of various concentration of sodium cholate (SC) with Imipramine [34].

\begin{tabular}{|c|c|c|c|c|c|c|c|c|c|c|c|}
\hline \multicolumn{4}{|c|}{ SC+Imipramine(300K) } & \multicolumn{4}{|c|}{ SC+Imipramine(310K) } & \multicolumn{4}{|c|}{ SC+Imipramine(320K) } \\
\hline CMC & $\begin{array}{l}\Delta \mathbf{G}_{\mathrm{m}}^{\circ} \\
(\mathrm{kJ} / \mathrm{mole})\end{array}$ & $\begin{array}{l}\Delta \mathbf{H}_{\mathrm{m}}^{\circ} \\
(\mathrm{kJ} / \mathrm{mole})\end{array}$ & $\begin{array}{l}\Delta \mathbf{S}_{\mathrm{m}}^{\circ} \\
(\mathbf{k J} / \text { mole })\end{array}$ & CMC & $\begin{array}{l}\Delta \mathbf{G}_{\mathrm{m}}^{\circ} \\
(\mathrm{kJ} / \mathrm{mole})\end{array}$ & $\begin{array}{l}\Delta \mathbf{H}_{\mathrm{m}}^{\circ} \\
(\mathrm{kJ} / \mathrm{mole})\end{array}$ & $\begin{array}{l}\Delta \mathbf{S}_{\mathbf{m}}^{\circ} \\
(\mathbf{k J} / \mathbf{m o l} \\
\text { e) }\end{array}$ & CMC & $\begin{array}{l}\Delta \mathbf{G}_{\mathrm{m}}^{\circ} \\
(\mathrm{kJ} / \mathrm{mole})\end{array}$ & $\begin{array}{l}\Delta \mathbf{H}_{\mathrm{m}}^{\circ} \\
(\mathrm{kJ} / \mathrm{mole})\end{array}$ & $\begin{array}{l}\Delta \mathbf{S}_{\mathrm{m}}^{\circ} \\
(\mathrm{kJ} / \mathrm{mole})\end{array}$ \\
\hline 0.0166 & -73.94 & -64.93 & 30.03 & 0.022 & -69.91 & -64.64 & 17 & 0.04 & -74.85 & -74.46 & 1.21 \\
\hline 0.019 & -69.22 & -63.9 & 17.73 & 0.0316 & -72.27 & -71.37 & 2.9 & 0.047 & -71.29 & -74.81 & -11 \\
\hline 0.0225 & -72.29 & -51.06 & 70.76 & 0.03 & -71.94 & -54.24 & 57.09 & 0.045 & -69.67 & -55.08 & 45.5 \\
\hline 0.0283 & -69.03 & -49.53 & 65 & 0.0425 & -69.65 & -53.13 & 396 & 0.056 & -53.06 & -51.19 & 5.84 \\
\hline 0.0133 & -67.49 & -73.12 & -18.76 & 0.02 & -59.77 & -68.75 & -28.96 & 0.04 & -74.68 & -93.03 & -57.31 \\
\hline 0.0107 & -73.74 & -60.7 & 43.46 & 0.015 & -78.57 & -66.20 & 39.9 & 0.025 & -77.16 & -71.68 & 17.12 \\
\hline- & - & - & - & 0.0125 & -73.06 & - & - & - & - & - & - \\
\hline 0.00928 & -73.60 & -39.41 & 113 & 0.0108 & -77.27 & -43.17 & 388 & 0.0162 & -73.94 & -43.8 & -94.1 \\
\hline 0.01 & -71.74 & -28.09 & 145 & 0.01 & -73.01 & -29.54 & 330 & 0.015 & -73.52 & -31.53 & 131 \\
\hline 0.00916 & -73.39 & -12.9 & 201 & 0.0078 & -72.01 & 150 & 716 & 0.011 & -80.97 & -15.36 & 205 \\
\hline
\end{tabular}


Table 8. Value of $\mathrm{cmc} c^{i d} / m M, C m c^{e x} / m M, X^{i d} \& X_{1}$ and the $\beta$ of the mixed micelle so $f$ Imipramine and anionic surfactants (SDC) at different mole fractions in aqueous solution [3].

\begin{tabular}{llllll}
\hline \multicolumn{6}{l}{ Imipramine+SDC } \\
\hline $\boldsymbol{\alpha}$ & $\mathbf{C m c}_{\mathbf{i d} / \mathbf{m M}}$ & $\mathbf{C m c}^{\mathbf{e x}} / \mathbf{m M}$ & $\mathbf{X}^{\text {id }}$ & $\mathbf{X}_{\mathbf{1}}$ & $\boldsymbol{\beta}$ \\
\hline 0.0181 & $9.25 \times 10^{-3}$ & 0.0166 & $2.79 \times 10^{-5}$ & 0.036 & -7.07 \\
$4.28 \times 10^{-3}$ & $9.13 \times 10^{-3}$ & 0.019 & $6.51 \times 10^{-6}$ & 0.274 & -18.8 \\
0.166 & 0.01 & 0.0225 & $3.01 \times 10^{-4}$ & 0.081 & -5.764 \\
0.08 & $9.87 \times 10^{-3}$ & 0.017 & $1.31 \times 10^{-4}$ & 0.041 & -5.65 \\
0.772 & 0.039 & 0.01 & $5.1 \times 10^{-3}$ & -0.543 & -28.94 \\
$3.95 \times 10^{-3}$ & $9.09 \times 10^{-3}$ & 0.0375 & $6 \times 10^{-6}$ & 0.356 & -23.09 \\
- & - & - & - & - & - \\
0.077 & $9.84 \times 10^{-3}$ & 0.0216 & $1.26 \times 10^{-4}$ & 0.0796 & -6.68 \\
1.7 & -0.013 & 0.0075 & $-3.69 \times 10^{-3}$ & 0.409 & -15.05 \\
0.0272 & $9.35 \times 10^{-3}$ & 0.00423 & $41.23 \times 10^{-5}$ & -0.129 & -11.61 \\
\hline
\end{tabular}

Table 9. Value of $\mathrm{cmc}^{i d} / \mathrm{mM}, \mathrm{Cmc} c^{e x} / \mathrm{mM}, X^{i d} \& X_{1}$ and the $\beta$ of the mixed micelles of Imipramine and anionic surfactants (SC) at different mole fractions in aqueous solution [3].

\begin{tabular}{llllll}
\hline \multicolumn{6}{l}{ Imipramine+SC } \\
\hline $\boldsymbol{\alpha}$ & $\mathbf{C m c}^{\text {id } / \mathbf{M m}}$ & $\mathbf{C m c}^{\mathbf{e x}} / \mathbf{m M}$ & $\mathbf{X}^{\text {id }}$ & $\mathbf{X}_{\mathbf{1}}$ & $\boldsymbol{\beta}$ \\
\hline 0.0266 & $9.33 \times 10^{-5}$ & 0.0166 & $2.06 \times 10^{-5}$ & 0.034 & -7.32 \\
0.136 & 0.0105 & 0.019 & $1.19 \times 10^{-4}$ & 0.048 & -5.98 \\
0.031 & $9.38 \times 10^{-5}$ & 0.0225 & $2.42 \times 10^{-5}$ & 0.073 & -8.32 \\
0.09 & $9.98 \times 10^{-5}$ & 0.0283 & $7.49 \times 10^{-5}$ & 0.109 & -7.86 \\
0.225 & 0.0117 & 0.0133 & $2.19 \times 10^{-4}$ & 0.159 & -9.13 \\
0.088 & $9.96 \times 10^{-5}$ & 0.0107 & $7.30 \times 10^{-5}$ & 0.106 & -9.01 \\
- & - & - & - & - & - \\
0.109 & 0.01 & 0.0092 & $9.26 \times 10^{-5}$ & 0.077 & -8.01 \\
0.148 & 0.0106 & 0.01 & $1.31 \times 10^{-4}$ & 0.078 & -7.60 \\
0.116 & 0.0102 & 0.00916 & $9.93 \times 10^{-5}$ & 0.437 & -26.8 \\
\hline
\end{tabular}

\section{Parameters for thermodynamic micellization}

$\Delta \mathrm{G}_{\mathrm{m}}^{\mathrm{o}}=$ Gibbs free energy of micellization,

$\Delta \mathrm{H}_{\mathrm{m}}^{\mathrm{o}}=$ Standard enthalpy of micelle formation

$\Delta \mathrm{S}_{\mathrm{m}}^{\mathrm{o}}=$ Standard entropy of micellization

$\mathrm{T}=$ Temperature

$\mathrm{R}=$ Gas constant

$\mathrm{X}_{\mathrm{cmc}}=$ Critical micelle concentration in mole fraction unit.

$\alpha=$ Conter ion dissociation

Parameters for development of model

$\mathrm{cmc}^{\mathrm{id}}=$ Concentration of ideal mixtures

$\mathrm{cmc}^{\mathrm{ex}}=$ Experimentally obtained critical micelle concentration

$x^{\text {id }}=$ Mole fraction of the more hydrophobic surfactantin the ideal mixed micelle,

$\mathrm{X}_{1}=$ Mole fraction of the more hydrophobic surfactant in the real mixed micelle

$\beta=$ Interaction parameter

$\mathrm{cmc}_{1}=$ Experimentally obtained $\mathrm{cmc}$ of the more hydrophobic (nonionic) surfactant (SDCandSC)

$\mathrm{cmc}_{2}=\mathrm{cmc}$ of Imipramine drug

$\alpha=$ Mole fraction of the more hydrophobic surfactant in the solution. $\alpha_{\mathrm{i}}=$ Mole fraction of the more hydrophobic surfactant in the solution.

\section{Acknowledgment}

The author Shweta Singh, JRF NUP are grateful to Dr. Arun Arora, Principal, Bhilai Institute of Technology, Durg for providing laboratory facilities for this work. This project are partially supported by BRNS, poject no.- 36(4) / 14/ 90/2014-BRNS/36014/29-2016

\section{References}

[1] Adane D. Fenta, Surface and thermodynamic studies of micellization of surfactants in binary mixtures of 1,2-ethane di ol and 1, 2, 3-propane triol with water. Department of Chemistry, College of Natural and Computational Science, Arbaminch University, Arbaminch, Ethiopia. Received 24 February, 2015; Accepted 25 March, 2015.

[2] Carlota Oliveira Rangel-Yagui, Adalberto Pessoa Junior, Leoberto Costa Tavares, Micellar solublization of drugs, J Pharm Pharmaceut Sci147-163,2005.

[3] Das A K, Hajra A K, (1992), Critical micellar concentrations of palmitoyl dehydroxyacetone phosphate and 1-palmitoylrac-glycerol 3-phosphate, J Biol Chem, 267, 14, 9731.

[4] D. m. Ćirin et al.:, (2012), Dodecyl sulfate-nonionic surfactant mixed micelles hem. Ind. 66 (1) 21-28.

[5] Dejan M. Cirin, Mihal jM. Posa, Veljko S. Krstonosic, MajaLj. Milanovic, (2012), Cconductometric study of Sodium dodecyl sulfate- non- ionic Surfactants (Triton X-100, A tween 20 , Tween 60 , Tween 80 or Tween85) mixed micelle in aqueous solution, Hem. Ind, 66 (1), 21-28.

[6] Dejan M. Cirin, Mihalj M. Posa, Veljko S. Krstonošić, 2011,Interactions between selected bile salts and Triton X-100 or sodium lauryl ether sulfate, Chemistry Central Journal5:89.

[7] G. Moodssac, A. Al Wardian, K. Glenn and R. Palepu,(2004),CanJChem,82, 1774.

[8] I. A. Khan, A. J. Khanam, M. S. Sheikh, Kabir-ud Din, (2011), Influence of ionic and nonionic hydrotropes on micellar behavior of a cationic Gemini surfactant butanediyl1,4-bis (dimethylcetylammoniumbromide), J. Colloid. Interface, 15;359 (2):467-73.

[9] J. Piret, A. Désormeaux, M. G. Bergeron, (2002), Sodium lauryl sulfate, amicro bicide effective against enveloped and nonenveloped viruses, Curr.DrugTargets3,17-30.

[10] J. Piret, Lamontagne J, Bestman Smith J, S. Roy, P.Gourde, A. Désormeaux, R. F. Omar, J. Juhász, M. G. Bergeron, (2000), Invitro and invivo evaluations of sodium lauryl sulfate and dextran sulfate as microbicides agains the rpessimplex and humanimmunod eficiency viruses, 38(1):110.

[11] J. L. Palous, M. Turmine, P. Letellier, (1998), Mixtures of non- ionic and ionic surfactants: Determination of mixed micelle composition using cross differentiation relations, J.Phys.Chem. B102,5886-5890.

[12] Kabir-ud Din, Rub M A, Naqvi AZ, (2010), Mixed micellization of antidepressant drug amitriptyline hydrochloride with cationicsurfactants, Colloids Surf B Biointerfaces, 80(2):206-12, Epub 2010 Jun 19.

[13] Kallol K Ghosh and Vidyacharan Baghel, (2008), Indian Journal of chemistry, Vol.47A, 1230-1233.

[14] Manivannan Rangasamy, Kugalur Ganesan Partthiban, Recent advance in novel drug delivery systems, IJRAP, 2010, 1, (2), 316-326.

[15] M. J. Rosen, D. Murphy, (1986), Synergism in binary mixtures of surfactants: V.Two-phaseliquid - liquid systems at low surfactant concentrations, J.Colloid Interface Sci. 110, 224-236. 
[16] M. Jahirul Islam, M. M. R.Choundri, S. M. F. Shahed, M. A. Subhan, (2009), Effect of some biologically important organic compounds on the micellar properties of sodium dodecyl sulphate, Proc. Pak. Acad. Sci. 46, 91-95.

[17] M. J. Rosen, B. Y. Zhu, (1986), Synergism in binary mixtures of surfactant: III. Betaine- containing systems, J. Colloid Interface Sci. 99, 427-434.

[18] M. N. Shala by, (2008), Synergistic behavior of binary mixed micellar solution, J. Dispersion Sci. Technol.29, 447-452.

[19] Mazer N A,(1985), Laser Light Scattering in Micellar systems in 'Dynamic Light Scattering: Applications'by R Pecora, Springer, 305-346.

[20] Mohammad Safi,(2013), Aggregation behavior of amphiphilic drug and bile salt mixtures at different compositions and temperatures, The Journal of Chemical Thermodynamics, 64:28-39.

[21] Navas A., Di'az, Garci'a F., Sa' nchez, A. Garci' a Pareja, (1998), Cholic acid behavior in water and organic solvent: study of normal and inverted aggregates, 142, 27-34.

[22] Nighat Razvi, Saeed Ahmad Siddiquiand Lubna Ghazal Khan, (2005), The effect of surfactant on the dissolution rate of ibuprofen tablets in ti. Chern. Pharm. Med. J. Vol. 2 (1), pp. 213-216.

[23] O. López, M. Cócera, E. Wehrli, J. L. Parra, A. De La Maza, (1999), Solubilization of liposomes by sodium dodecyl sulphate: new mechanism based on the direct formation of mixed micelles, Arch. Biochem .Biophys. 367, 153-160.

[24] Peizhu Zheng, Xianshuo Zhang, Jian Fang, and Weiguo Shen, Thermodynamic Study of Mixed Surfactants of Polyoxyethylene tert-Octyl Phenyl Etherand Dodecyl trimethyl ammonium Bromide, J. Chem. Eng. Data, 2016, 61(2), pp 979-986.

[25] Piszkichwicz D., (1977), Kinetics Study of Malachite Green Fading, J. Am. Chem. Soc, 99, 7695.

[26] Prajapati K. and Patel S., 2012, Micellization of Surfactants in Mixed Solvent of Different Polarity, Archives of Applied Science Research, 4 (1):662-668.

[27] Reflection paper on the pharmaceutical development of intravenous medicinal products containing active substances solubilised in micellar systems, (05March2012),
EMA/CHMP/QWP/799402/2011ComplianceandInspection.

[28] Reflection paper on the pharmaceutical development of intravenous medicinal products containing active substances solubilised in micellar systems (non-polymericsurfactants), 23 Sep 2010 EMA/ CHMP/ QWP/ 799402/ 2011 Compliance and Inspection.

[29] Sar Santosh K. and Rathod Nutan, (2011), Mixed micelle formation between amino acid-based surfactants and phospholipids. Sci. 359, 467-473.

[30] Sandhiya Jatwani, Avtarch and Rana, Gurpreet Singh and Geeta Aggarwal, (2004), An overview on solubility enhancement techniques for poorly soluble drugs and solid dispersion as an eminent rategic approach, IJPSR (2012), vol. 3 , issue 04 .

[31] S. A. Baeurt, and J. Kroener, (2004) ,Modeling effective interactions of micellar aggregates of ionic, J Math Chem. 36:409-421.

[32] Santanu Paria, (2006), The mixing behavior of n-alkyl pyridinium bromide -NP 9 mixed surfactant systems, Colloids of surface, 281, 1-3, 113-118.

[33] Shweta \& Santosh kSar, (2014), Micellization of some bile salt in binary aqueous solvent mixture, $\mathrm{J}$ of surfactants \& Detergent, 17, 143-150.

[34] S. Tiwari and Ghosh K. K.; (2008), Micellization of cetyl tributyl phosphonium Bromide in some Binary Aqueous Solvents mixtures, Tenside Surf. Det., 45, 5.

[35] Saeed Ahmad Siddiqui, Nighat Razvi, and Lubna Ghazal Khan, 2005, the effect of surfactant on the dissolution rate of ibuprofen tablets,in ti.chern.pharm. med. j. vol. 2(1), pp. 213216.

[36] Sujeet kumar chatterjee and tulasi Prasad niraula, ajaya bhattarai et al (2013), effects of concentration, temperature and solvent composition on density and apparent molar volume of the binary mixtures of cationic-anionic surfactants in methanol-water mixed solvent media, springer plus, 2:280.

[37] Williamn. charman, Christopher J. H. Porter, Sabena Mithani, Jennifer B. Dressman, (1997), Physicochemical and Physiological Mechanisms for the Effects of Food on Drug Absorption: The Role of Lipids and $\mathrm{pH}$, Volume86, Issue 3, Pages 269-282. 